\title{
Permeability Enhancement and Gas Drainage Effect in Deep High Gassy Coal Seams via Long-Distance Pressure Relief Mining: A Case Study
}

\author{
Xiang He $\mathbb{i D}^{1,2}$ Ke Yang ${ }^{1 D},{ }^{3,4,5}$ Penghua Han $\mathbb{D}^{1},{ }^{1,2}$ Wenjie Liu, ${ }^{3,4}$ Zhonghao Zhang, \\ and Huan $\mathrm{Wu}^{6}$ \\ ${ }^{1}$ School of Energy and Mining Engineering, China University of Mining \& Technology (Beijing), Beijing 100083, China \\ ${ }^{2}$ Beijing Key Laboratory for Precise Mining of Intergrown Energy and Resources, \\ China University of Mining \& Technology (Beijing), Beijing 100083, China \\ ${ }^{3}$ School of Energy and Safety, Anhui University of Science and Technology, Huainan Anhui 232001, China \\ ${ }^{4}$ State Key Laboratory of Mining Response and Disaster Prevention and Control in Deep Coal Mines, \\ Anhui University of Science and Technology, Huainan Anhui 232001, China \\ ${ }^{5}$ Institute of Energy, Hefei Comprehensive National Science Center, Anhui, Hefei 230031, China \\ ${ }^{6}$ Guqiao Coal Mine, Huainan Mining (Group) Co., Ltd, Anhui, Huainan 232001, China
}

Correspondence should be addressed to Ke Yang; keyang2003@163.com

Received 23 November 2020; Revised 17 February 2021; Accepted 6 March 2021; Published 22 March 2021

Academic Editor: Yu-Wei Chen

Copyright (c) 2021 Xiang He et al. This is an open access article distributed under the Creative Commons Attribution License, which permits unrestricted use, distribution, and reproduction in any medium, provided the original work is properly cited.

Coal 3 in group A is employed as a protective layer to release long-distance coal 4 in group B in Paner colliery (approximately $80 \mathrm{~m}$ vertical interval) as the mining depth extends downward, which is the first engineering test in the Huainan coal mining area. To evaluate the validity of the scheme, the permeability distribution, and evolution law, gas pressure distribution characteristics, swelling deformation, pressure relief range, and gas drainage volume of the protected coal seam are analyzed using a FLAC3D numerical simulation and field measurements. Therefore, different stress-permeability models are adopted for caved, fractured, and continuous deformation zones, and a double-yield model is applied in the goaf based on compaction theory to improve the accuracy of the numerical simulation. The results indicate that the extraction of coal 3 has a positive effect on permeability enhancement and pressure relief gas drainage. However, the dip angle of coal measurements causes asymmetric strata movement, which leads to the pressure relief and permeability enhancement area shifting to the downhill side, where the permeability enhancement effect of the downhill side is better than that of the uphill side. The permeability enhancement zone is an inverted trapezoid, but the effective pressure relief range is a positive trapezoid. The permeability of the protected coal seam in the pressure relief zone is significantly higher than that in the compressive failure zone. The permeability in the pressure relief zone will decrease again due to the recompaction of the coal seam with an advancement of the longwall face. Thus, pressure relief gas drainage is suggested during long-distance protective coal seam mining to eliminate gas hazards.

\section{Introduction}

Coalbed methane is an associated product of coal resources. It is also a clean resource, but it threatens coal mining safety. Pressure relief mining has been the primary method to remove gas and coal outbursts and achieve simultaneous coal and gas extraction in deep, high gas, and low-permeability coal seams. The Huainan mining area is characterized by typical "three high and one low" (high ground stress, high gas pressure, high gas content, and low permeability) multiple coal seam mining [1-3]. As shown in Figure 1, gas accidents and death tolls should still be given more attention. With the extension of mining depths, the occurrence and mining settings of coal seams have become increasingly complicated, resulting in an increasing risk of coal and gas outbursts [4-6]. Therefore, the effect of pressure relief and 


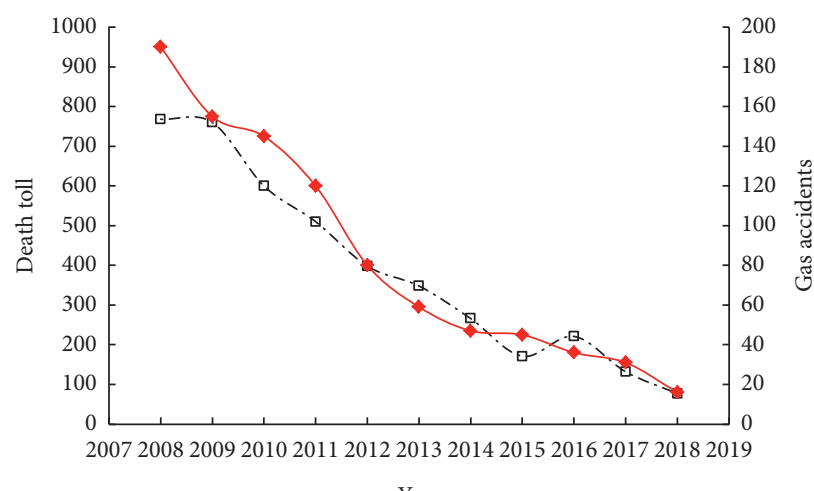

Year

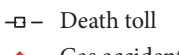

$\bullet$ Gas accident

(a)

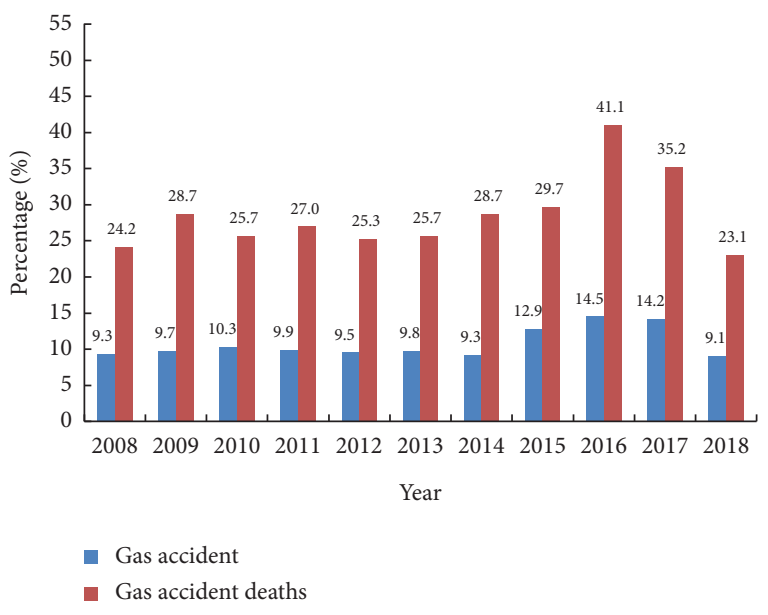

(b)

Figure 1: (a) Number of gas accidents and death tolls. (b) Percentage of gas accidents and related deaths.

permeability enhancement of deep high-gas coal seams is the basis for eliminating the threat of coal and gas outbursts and improving the efficiency of gas extraction.

In China, predrainage should be conducted before longwall mining to reduce the gas pressure and gas content below the safety limits of $0.74 \mathrm{MPa}$ and $8.0 \mathrm{~m}^{3} / t$ for high-gas coal seams, respectively [7]. However, it is difficult to achieve the national standard by simple drainage due to the low permeability and strong adsorption characteristics in most of the high-gas coal seams in China $[8,9]$. As listed in Table 1, the coalbed permeability of most mining areas in China is $10^{-4}-10^{-3} \mathrm{mD}$, which is much lower than that of coal seams in Australia, the United States, and other countries $[10,11]$. Thus, the integrated method of protective seam mining and gas drainage is essential to eliminate mine disasters, such as coal and gas outbursts, and achieve simultaneous coal and gas extraction [12-14].

The extraction of the protective coal seam (PCS) could release the stress in the surrounding rock, and the protected coal seam (PDCS) depressurizes in the pressure relief area. As the pressure of the PDCS is relieved, the gas adsorption capacity is weakened, and the amount of free gas increases. The extraction of the PCS also creates fractures in the PDCS, which promote gas desorption and gas flow. Eventually, the gas pressure and gas content decrease and prevent coal and gas outbursts. Based on the above analysis, researchers have conducted numerous works and achieved fruitful results. Yuan established the theory of high-level annular fractured bodies for efficient gas extraction in low-permeability coal seams and determined the corresponding discrimination methods, providing a set of scientific research methods and engineering design methods for the development of coal and gas coextraction theory and engineering practice $[2,3]$. Li et al. developed a dynamic evolution model of the ellipsoidal zone of mining cracks, analyzed the mechanism of pressure relief gas drainage in the ellipse zone, and proposed that the key to ensuring a good pressure relief gas drainage effect lies in mastering the law of temporal and spatial evolution of the stress field, fracture field, and seepage field of the surrounding rock [15]. Cheng et al. used the theoretical model of permeability to explore the changing law of the permeability of deep coal seams and believed that to effectively increase the permeability of the coal seams, only the ground stress can be reduced [16]. Tu et al. studied the permeability distribution characteristics and evolution law of the goaf through field measurements and numerical simulations and introduced the reduction multiple of the gas emission coefficient to reflect the protective layer pressure relief and permeability enhancement effect [17]. Xu et al. combined the key layer theory with the actual measurement of the on-site gas drainage effect and divided the overlying rock from top to bottom into a difficult desorption zone, a pressure relief desorption zone, and a gas conduction fracture zone [18]. Zhu et al. introduced governing equations of gas seepage field and deformation field in mining coalrock mass based on the physical coupling process between coal-rock mass deformation and pressure relief gas migration, the coupling variable of mining coal-rock mass [19]. Yuan et al. found that with the increase in interlayer distance, the pressure relief curve evolves from pattern " $\cap$ " to pattern " $\wedge$ " and corresponding pressure relief region becomes narrower through similar material simulation experiment of steeply inclined upper protective layer mining [20].

At present, field measurements and numerical simulations have been widely employed to evaluate the effect of pressure relief and permeability enhancement in protected coal seams [21]. Although field measurements have a high cost, complicated operation, and poor security, they have a more guiding significance for engineering applications. Tests on the residual gas content or pressure of the PDCS after PCS mining are widely employed, but monitoring the evolution of permeability and stress changes during PCS mining is difficult [22-24]. Fortunately, numerical simulations could overcome these difficulties and well evaluate the pressure relief mining performance. Most of the evaluations depend on indirect indexes, e.g., failure zones, pressure relief zones, and fracture development. These indexes cannot quantitatively describe 
TABLE 1: Coalbed permeability in primary coal mining countries $[10,11]$.

\begin{tabular}{lcc}
\hline Country & Mining area & Permeability (mD) \\
\hline Germany, Poland & Sydney basin & $10^{-2}-10^{-1}$ \\
Australia & Bowen basin & $10^{-3}-1.5 \times 10^{-1}$ \\
& San Juan basin & $10^{-2}-10^{2}$ \\
America & Black warrior basin & $10-1.5 \times 10^{2}$ \\
& Most mining areas & $5-50$ \\
China & Pingdingshan mining area & $10^{-4}-10^{-3}$ \\
& Fengcheng, Shuicheng, Hegang, Liulin, and Kailuan mining areas & $10^{-4}-2.28 \times 10^{-2}$ \\
\hline
\end{tabular}

permeability evolution and thus cannot guide subsequent seepage calculations and mining activities [25-27]. Both methods have advantages and disadvantages; thus, the integrated method has been widely employed to appraise the effect of pressure relief and permeability enhancement.

The numerical models of pressure relief mining were constructed based on the loading and unloading of gascontaining coal under different paths. In general, the uniaxial compressive strength of gas-containing coal decreases linearly with increase in gas pressure [28]. It is found that the dynamic compressive strength of gas-containing coal under coupled load decreases with the increasing initial gas pressure using a modified split Hopkinson pressure bar (SHPB) system [29]. The evolution of methane permeability of coal heavily depended on stress-strain stages. The permeability decreased with the increase in deviatoric stress at the initial compaction and elastic deformation stages, while it increased with the increase in deviatoric stress at the stages of yield deformation, stress sharp drop, and residual stress [30]. The loading process leads to a drastic drop in the caved zone porosity causing the permeability reduction. During the unloading process, only the permeability loss caused by the particle deformation can be recovered [31]. The sensitivity of axial permeability to the confining stress is much larger than that to the axial stress [32].

Numerous studies on pressure relief mining and gas drainage have been conducted, and favorable results have been achieved. However, as the mining depth extends downward, the more complicated geologic settings result in poor gas extraction and a greater risk of mine hazards. The \#3 coal seam of the Paner coal mine has entered deep mining, and remote pressure relief of the \#4 coal seam is an attempt in the mining area, which has guiding significance for other similar geological settings in the future. Based on this background, this study analyzes the permeability distribution and evolution characteristics, gas pressure, pressure relief range, dynamic change in the gas drainage volume, and coal seam expansion deformation using a FLAC3D seepage module simulation and a field engineering measurement method to judge the feasibility of long-distance pressure relief mining in deep high-gas coal seams.

\section{Engineering and Geological Settings}

The Paner coal mine is one of the main production mines in the Huainan mining area, located in northern Anhui Province, China (Figure 2(a)). Coal measure strata with 9 minable coal seams are distributed from bottom to top: group $\mathrm{A}$, group $\mathrm{B}$, and group $\mathrm{C}$. The average vertical distance between group A and group B is $80 \mathrm{~m}$ and that between group B and group C is $70 \mathrm{~m}$ (Figure 2(b)). Coals $5-1$ or $6-1$ have been selected for pressure relief of coal 4 for quite some time. However, it is still difficult to control the gas in the process of the coal 4 mines, resulting in secondary extraction being required, which costs too much money and manpower. Therefore, coal 3 mining in group A to long-distance release coal 4 in group B has been performed, which is the first test in the Huainan mining area. Coal seams 3 and 4 are high-gas outburst coal seams with an average dip angle of $13^{\circ}$ and an average vertical interval of approximately $80 \mathrm{~m}$. The average thickness of coal 4 is $3 \mathrm{~m}$, the gas content and gas pressure are $7.79 \mathrm{~m}^{3} / t$ and $1.5 \mathrm{MPa}$, respectively, and the permeability coefficient is $3.8 \times 10^{-4} \mathrm{mD}$. Coal 3 is the PCS with a gas content of $11 \mathrm{~m}^{3} / t$ and a gas pressure of $2.6 \mathrm{MPa}$ and $5.4 \times 10^{-3} \mathrm{mD}$.

Longwall fully mechanized panel 11223 is the first panel of 3 coal with a panel width of $180.0 \mathrm{~m}$ and a mining height of $5.0 \mathrm{~m}$. Due to geological factors, the panel was divided into eastern and western districts with a rotation angle of $19^{\circ}$. The total panel length is $1466 \mathrm{~m}$, including $876 \mathrm{~m}$ in the west district and $590 \mathrm{~m}$ in the east district (Figure 2(b)). The strata structure in the eastern district of 11223 was analyzed based on rock mechanics tests and key stratum theory, and it was concluded that the $6.8 \mathrm{~m}$ thick sand/mudstone interbed in the overburden was key stratum 1 and the $12 \mathrm{~m}$ thick fine sandstone was key stratum 2. Because the key stratum calculation was without strata above coal 4 , the position of the primary key stratum was uncertain. Thus, the calculated key strata were named key stratum 1 and key stratum 2 from bottom to top (Figure 2(c)).

The burial depth of coal 3 of the Paner coal mine is between 600 and $800 \mathrm{~m}$. Obvious deep mining characteristics were found in the process of the working face advancement and roadway support. As shown in Figure 3, coal wall spalling and large roadway deformation occurred frequently, resulting in reduced productivity.

\section{Permeability in the "Three Zones"}

3.1. Permeability Characteristics of the Three Zones. Three successive distinct zones, the caved, fractured, and continuous deformation zones, have been identified above the panel gob based on the behavior of mining-induced vertical fractures in the underground mines. As shown in Figure 4, the stress state 


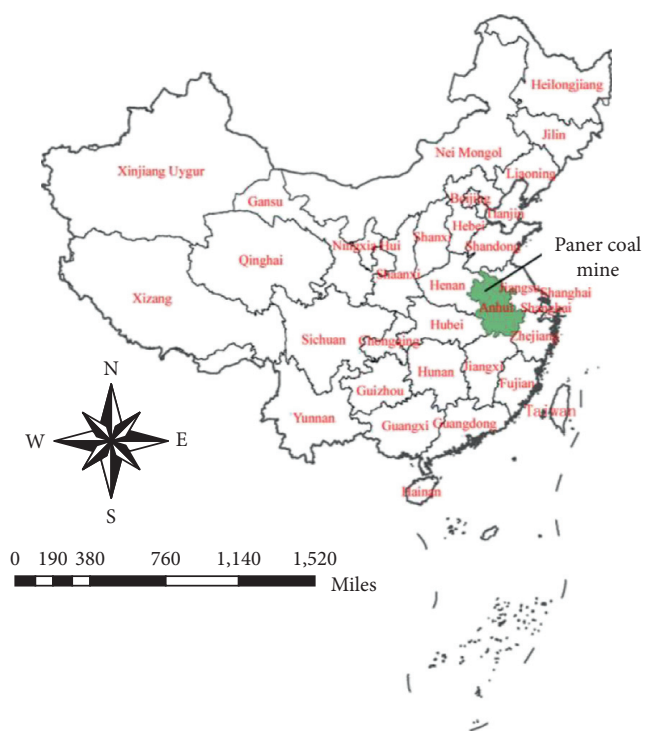

(a)

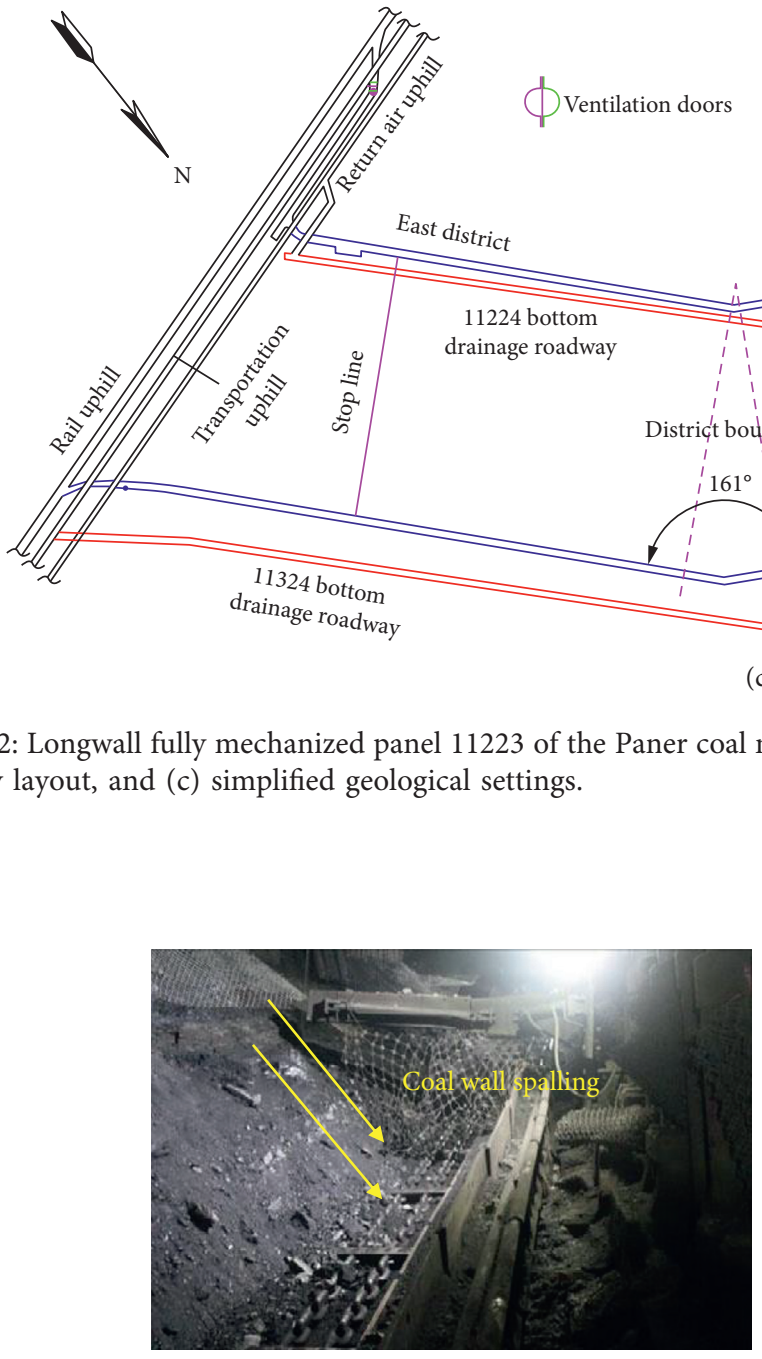

(a) roadway layout, and (c) simplified geological settings.

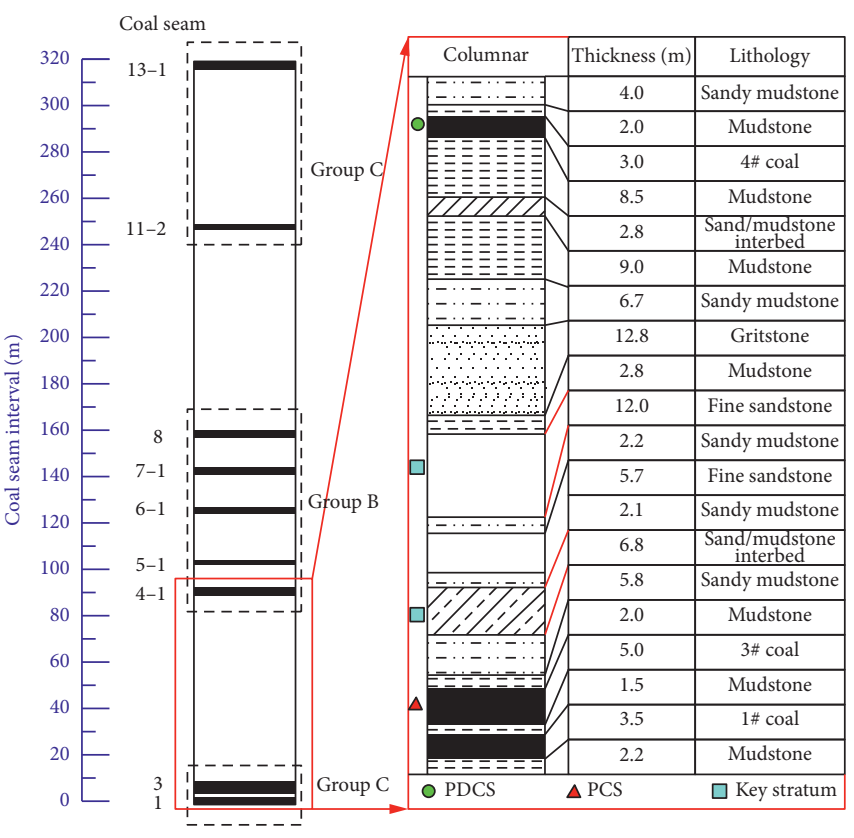

(b)

(c)

FIGURE 2: Longwall fully mechanized panel 11223 of the Paner coal mine in the Huainan mining area: (a) colliery location, (b) panel and

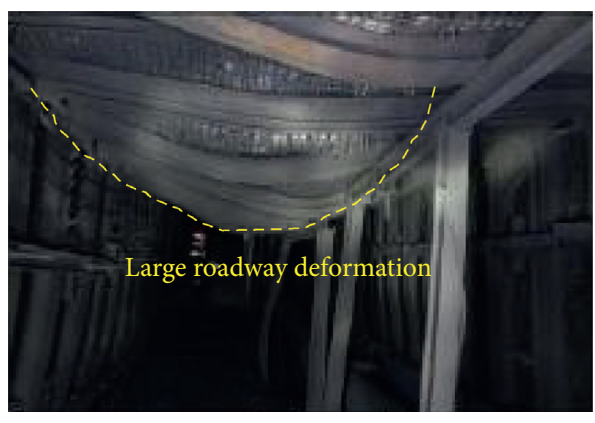

(b)

FIgUre 3: Deep mining characteristics in the Paner coal mine: (a) coal wall spalling; (b) large roadway deformation. 


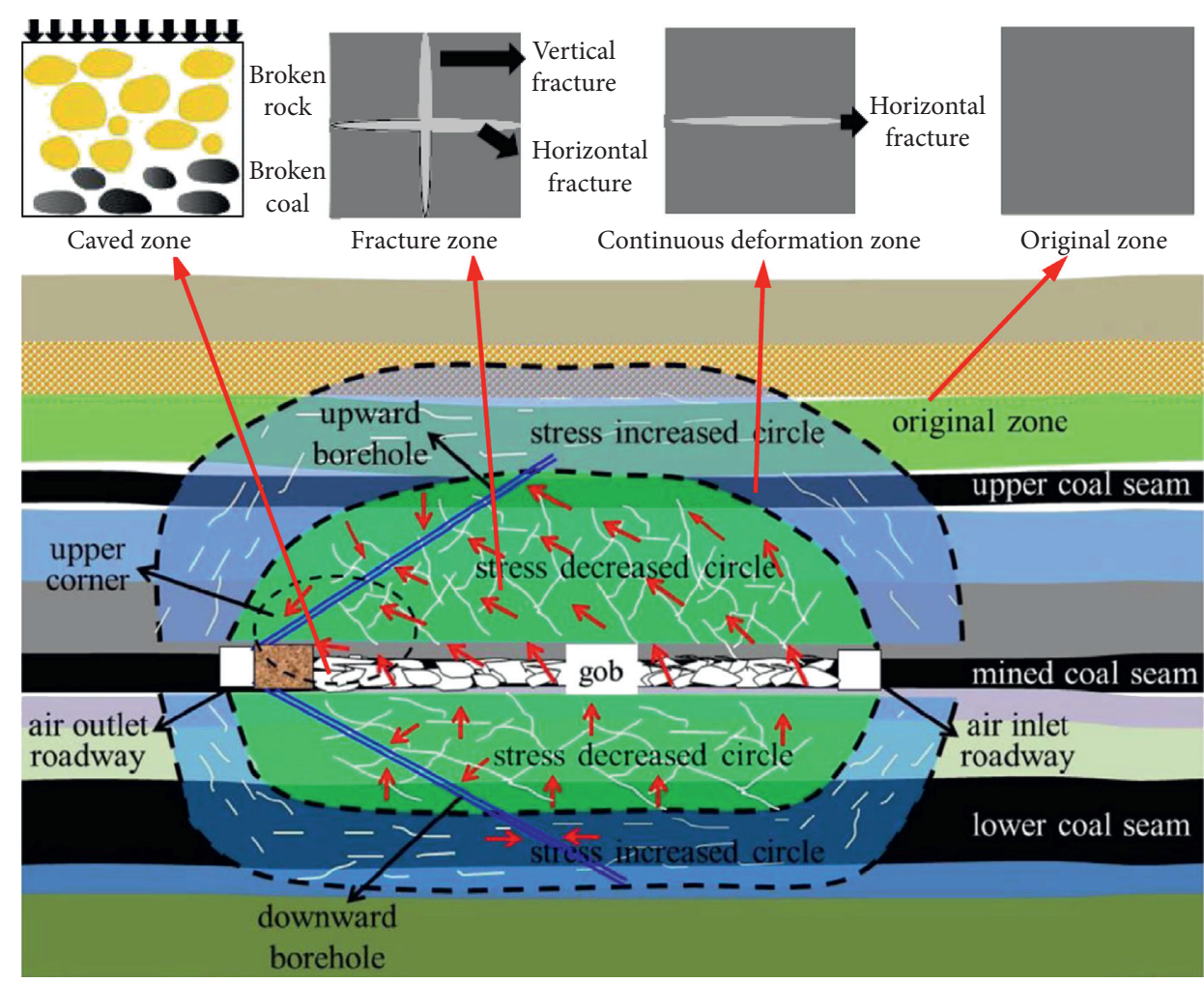

Figure 4: Different damage zones in pressure relief mining (modified from [26]).

and fracture distribution in the three zones are quite different, leading to an obvious difference in the pressure relief effect. In the caved zone, the broken rocks are irregular in shape and very disorderly in arrangement. The expansion coefficient in this zone reaches 1.3-1.5 with a larger space to gather free gas. In the fracture zone, the broken rocks are arranged in order with vertical and horizontal fractures, which are the primary channels for gas flow. In the continuous deformation zone, the overlying strata move continuously and integrally with several separation fractures for gas desorption. Therefore, the PDCS in different zones will exhibit instinct effects of pressure relief and gas drainage.

3.2. Permeability Model in Different Zones. Laboratory tests show that the rock/coal permeability decreases with an increasing stress before reaching the peak stress, and that the main reason affecting the rock permeability is the opening and closure of the joint and fissures in the rock $[33,34]$. However, during the failure process of rock after the peak stress, its permeability increases sharply.

The permeability in the caved zone agrees with the change law of the rock stress permeability after the peak. According to numerous experimental results, the quantitative relation between the original permeability $K_{g 0}$ and the volume strain $\varepsilon_{\mathrm{vol}}$ in the goaf is as follows [35]:

$$
K_{g 0}=-4 \times 10^{-16} \varepsilon_{v o l}^{3}-6 \times 10^{-15} \varepsilon_{v o l}^{2}-7 \times 10^{-14} \varepsilon_{\mathrm{vol}}+10^{-11} .
$$

Based on the theory of goaf compaction, the relationship between vertical stress $\sigma_{v}$, vertical strain $\varepsilon$, bulk modulus $K$, shear modulus $G$, and maximum vertical strain $\varepsilon_{m}$ in the caved zone is given in reference [36], as shown in the following equation:

$$
\begin{aligned}
K & =\frac{4 G}{3}, \\
& =\frac{\sigma_{v}}{2 \varepsilon}, \\
& =\frac{E_{0}}{2\left(1-\varepsilon / \varepsilon_{m}\right)} .
\end{aligned}
$$

Numerous microscopic and macroscopic fractures are distributed in the rock mass in the fracture zone. Durucan and Whittles $[37,38]$ concluded that the permeability of fractured rock masses is related to the maximum and minimum principal stresses based on the summary and analysis of laboratory results, and the following quantitative relation is satisfied:

$$
K_{f}=K_{f 0}\left(\frac{\sigma_{1}+\sigma_{3}}{2}\right)^{0.816}
$$

where $K_{f}$ is the permeability of fractured rock; $\sigma_{1}$ and $\sigma_{3}$ are the maximum and minimum principal stresses, respectively; and $K_{f 0}$ is the permeability at $\left(\sigma_{1}+\sigma_{3}\right) / 2=1$.

The rock mass in the continuous deformation zone bends and subsides due to the disturbance of coal mining but 
is not damaged. For the stress-permeability relationship of intact rock masses, Ren and Edwards [39] concluded that the quantitative relation between permeability and stress is exponential, as follows:

$$
\begin{aligned}
& K_{h}=K_{h 0} e^{-0.25\left(\sigma_{x x}-\sigma_{x x 0}\right)}, \\
& K_{v}=K_{v 0} e^{-0.25\left(\sigma_{y y}-\sigma_{y y 0}\right)},
\end{aligned}
$$

where $K_{h}$ and $K_{v}$ are the horizontal and vertical permeabilities of the intact rock mass, respectively, $K_{h 0}$ and $K_{v 0}$ are the original horizontal and vertical permeabilities of the intact rock mass, respectively, $\sigma_{x x}$ and $\sigma_{y y}$ are the horizontal and vertical stresses of the intact rock mass, respectively, and $\sigma_{x x 0}$ and $\sigma_{y y 0}$ are the original horizontal and vertical stresses of the intact rock mass, respectively.

3.3. Heights of the Caved and Fracture Zones. An empirical equation to predict the extent of the caved zone has been developed in China from a diverse set of data with different lithological and geometric characteristics. The average height of the caved zone can be determined by equation (5) for flat or nearly flat seams, which employs the longwall mining method with full caving. Based on many field data obtained on stabilized gob conditions in Chinese coalfields, a model (equation (6)) to estimate the average height of the water conducting fracture zone (WCFZ, including the caved zone and fracture zone) for hard, medium hard, soft, and weak rocks was also developed.

$$
\begin{aligned}
& H_{c}=\frac{100 M}{c_{1} M+c_{2}}, \\
& H_{f}=\frac{100 M}{c_{3} M+c_{4}},
\end{aligned}
$$

where $H_{c}$ and $H_{f}$ are the average height of the caved zone and WCFZ, $M$ is the mining height, and $c_{1}, c_{2}, c_{3}$, and $c_{4}$ are coefficients that depend on strata lithology, $\mathrm{m}-1$, which are constant (Table 2).

\section{Numerical Simulation for Long-Distance Pressure Relief Mining}

4.1. Model Setup. The FLAC3D numerical model of upward pressure relief mining was established by taking panel 11223 of the Paner coal mine as a prototype. The model dimensions were $400 \mathrm{~m}$ long $\times 300$ wide $\times 168 \mathrm{~m}$ high with 58010 zones. As shown in Figure 5, the panel width was $180 \mathrm{~m}$, and the roadway dimensions were $5 \mathrm{~m}$ wide $\times 5 \mathrm{~m}$ high. The coal seam dip angle was $13^{\circ}$, and the normal distance between coal 3 (PCS) and coal 4 (PDCS) was $79.2 \mathrm{~m}$. A fixed boundary was set at the bottom of the model, a roller boundary was set around the model, and $10 \mathrm{MPa}$ of pressure was applied on the top to simulate the overlying strata without a simulation. The width of the grid is $5 \mathrm{~m}$, the height of the grid is stratified according to the thickness of the strata and is less than $3 \mathrm{~m}$, and the coal seam grid is densified twice. After the coal seam is mined, the height of the goaf is set as $16.7 \mathrm{~m}$ based on the histogram and equation (5). The caving angle of the uphill side is $68^{\circ}$ and the downhill side is $58^{\circ}$, and the strike caving angle is $60^{\circ}$ according to the field test results.

According to the relationship between the stress distribution characteristics and permeability in the "three zones" of overburden, a secondary development of the seepage module was conducted using fish language. The evolution law of surrounding rock permeability during longdistance pressure relief mining of coal 3 to release coal 4 was simulated. The caved zone was defined by equation (5) and caving angles; the fracture zone was defined plastic zone except goaf in FLAC3D; the continuous deformation zone was the elastic zone. Stress-permeability relation of the caved, fracture, and continuous deformation zones was determined by the unit pointer to identify different zones. Three zones in the FLAC3D model are continuous and permeability changes continuously.

The Mohr-Coulomb criterion that conventionally judges the shear failure of soils and rocks was adopted in the excavation simulation (Figure 6(a)). The physical and mechanical parameters of the coal seams and strata are listed in Tables 3 and 4 . The numerical parameters are shown in Table 3 determined by physical and mechanical tests of rock samples which collected from the roof of the panel 11223 .

Based on the compaction theory of goaf rock masses, the double-yield model was applied in the gob elements (Figure 6(b)), which describes materials that experience significant irreversible compaction in addition to shear yielding, such as hydraulically placed backfill or lightly cemented granular material. The detailed theory and implementation for these models are in the FLAC3D documentation [33]. The original permeabilities of various rocks and disturbed rock strata were summarized by Esterhuizen et al. [41]. The model was reliable and has been verified by Huainan mining field engineering $[42,43]$.

4.2. Permeability Distribution and Evolution. As shown in Figure 7, the permeability of coal 4 increases gradually from the margin to the center to $0.817 \mathrm{md}$, which is 2149 times larger, indicating that coal 3 has a significant effect on the pressure relief and permeability enhancement for coal 4 . The variation range of permeability of coal 4 is in the " 0 " shape after coal 3 is mined $300 \mathrm{~m}$, as shown in Section 1, with strike direction symmetry $Y=200 \mathrm{~m}$ and dip direction symmetry $X=120 \mathrm{~m}$. The dip angle of the coal seam leads to asymmetric strata movement, and the pressure relief and permeability increasing zones of the PDCS exhibit obvious skewness characteristics in the $X$ direction (dip direction). On the one hand, the pressure relief and permeability enhancement zones tend to be symmetrical along $X=120 \mathrm{~m}$, rather than $X=150 \mathrm{~m}$ in the midpoint of the working face, and the whole zones shift $30 \mathrm{~m}$ to the side of the headgate (transportation roadway). On the other hand, as the working face advances, the overburden fractures above the panel center are closed, and the permeability of coal 4 is restored to the original permeability state. However, when $X=120 \mathrm{~m}$ on the left side of the middle line, the permeability reaches 
TABLE 2: Coefficient for average height of the caved zone and WCFZ [40].

\begin{tabular}{|c|c|c|c|c|c|}
\hline \multirow{2}{*}{ Strata lithology } & \multirow{2}{*}{ Compressive strength ( $\mathrm{MPa})$} & \multicolumn{4}{|c|}{ Coefficients } \\
\hline & & $C_{1}\left(\mathrm{~m}^{-1}\right)$ & $C_{2}(-)$ & $C_{3}\left(\mathrm{~m}^{-1}\right)$ & $C_{4}(-)$ \\
\hline Strong and hard & $>40$ & 2.1 & 16 & 1.2 & 2 \\
\hline Medium strong & $20-40$ & 4.7 & 19 & 1.6 & 3.6 \\
\hline Soft and weak & $<20$ & 6.2 & 32 & 3.1 & 5 \\
\hline
\end{tabular}

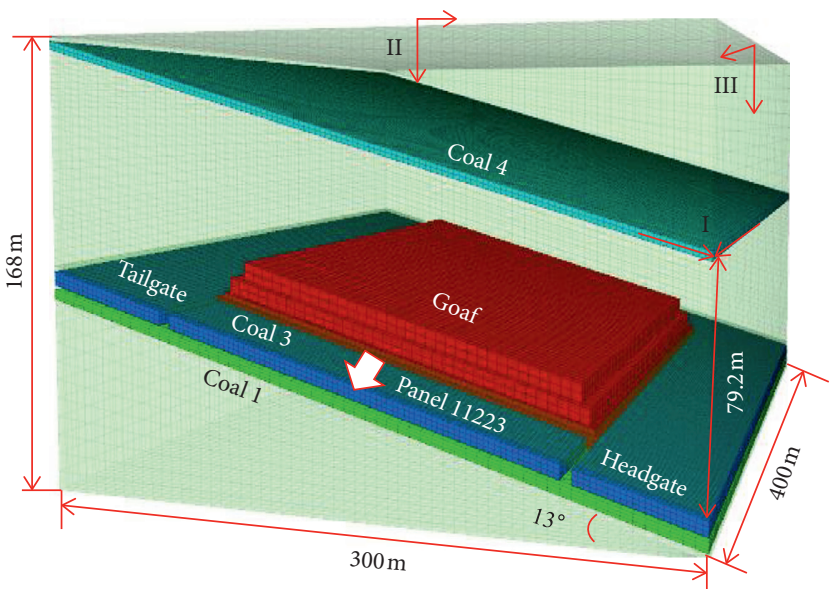

(a)
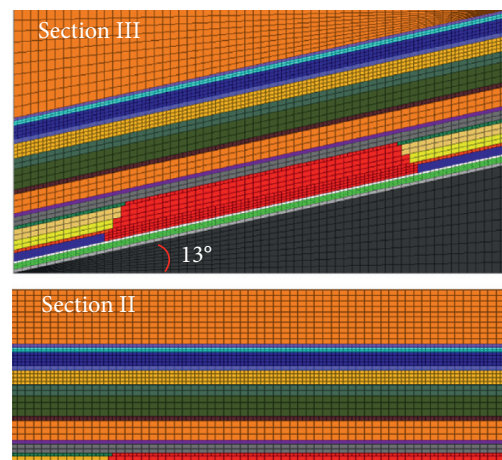

\section{+.}

Advancing direction

Coal_1

Coal_3

Coal_4

Finesandstone_1

Goaf_1

Gritstone

Keystratum_1

Keystratum_2

Mudstone_1

Mudstone_2

Mudstone_3

Mudstone_4

Mudstone_-5

Mudstone-7

Mudstone_7

Sandymudstone_1

Sandymudstone_2

Sandymudstone_3

Sandymudstone_4

Sandymudstone_5

Sandymudstone_6

(b)

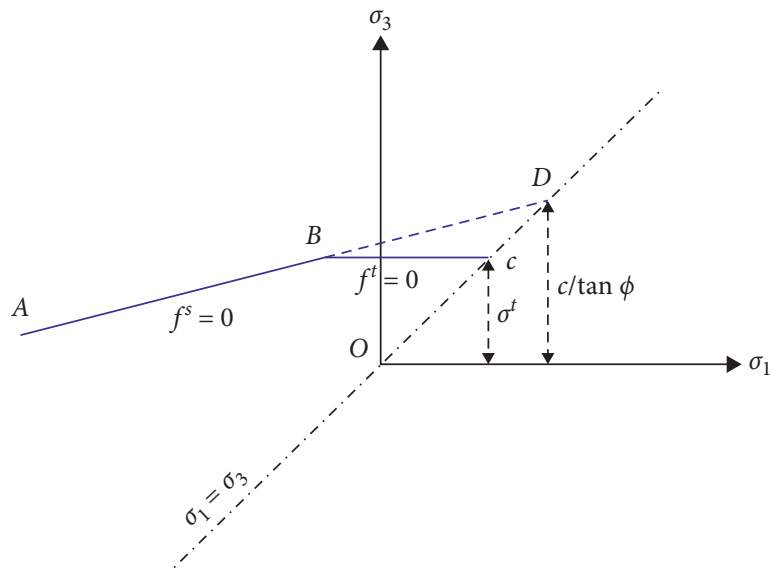

(a)

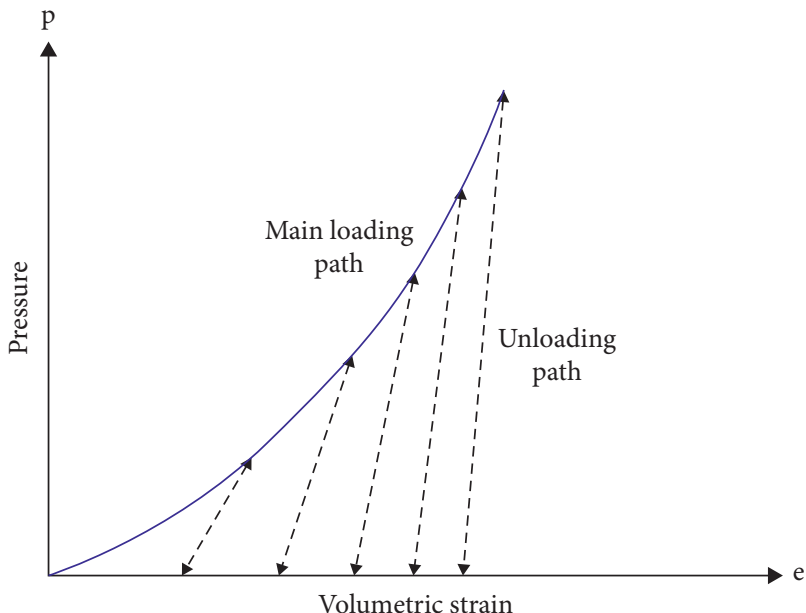

(b)

FIgURE 6: The failure criterion of the Mohr-Coulomb criterion and the behavior exhibited by the double-yield. (a) Mohr-Coulomb model. (b) Double yield model.

TABLE 3: Physical and mechanical parameters of coal seams and strata in the model.

\begin{tabular}{|c|c|c|c|c|c|c|}
\hline Lithology & Elastic modulus (GPa) & Poisson's ratio & $\begin{array}{c}\text { Internal friction } \\
\text { angle }\left({ }^{\circ}\right)\end{array}$ & $\begin{array}{c}\text { Tensile } \\
\text { strength }(\mathrm{MPa})\end{array}$ & Cohesion (MPa) & Density $\left(\mathrm{kg} / \mathrm{m}^{3}\right)$ \\
\hline Sandy mudstone & 11.15 & 0.22 & 35 & 1.6 & 2.25 & 2565 \\
\hline Mudstone & 10.45 & 0.30 & 32 & 1.4 & 1.9 & 2389 \\
\hline Coal seam & 2.43 & 0.31 & 30 & 0.5 & 1.3 & 1460 \\
\hline Fine sandstone & 20.82 & 0.17 & 37 & 3.0 & 5.9 & 2684 \\
\hline Gritstone & 15.15 & 0.13 & 36 & 1.2 & 3.2 & 2704 \\
\hline Sand/mudstone interbed & 21.64 & 0.19 & 35 & 2.0 & 2.4 & 2576 \\
\hline
\end{tabular}


TABLE 4: Cap pressure table of the double-yield gob elements [41].

\begin{tabular}{lcccccccc}
\hline Strain & 0.0 & 0.02 & 0.05 & 0.07 & 0.1 & 0.12 & 0.15 & 0.17 \\
\hline $\begin{array}{l}\text { Pressure (MPa) } \\
\text { Bulk modulus 0.60 GPa }\end{array}$ & 0.0 & 0.1 & 0.3 & 0.6 & 1.25 & 2.25 & 5.0 & 10.0 \\
\hline
\end{tabular}

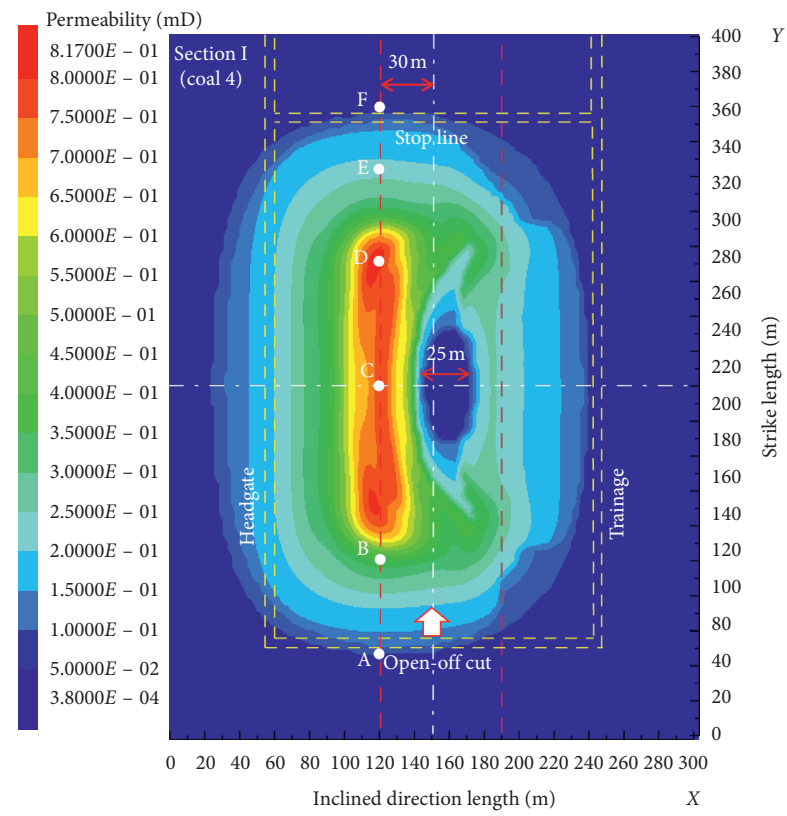

(a)

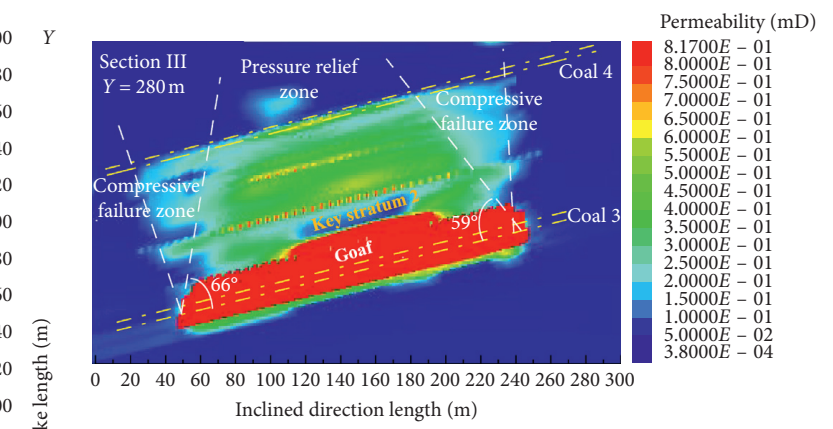

(b)

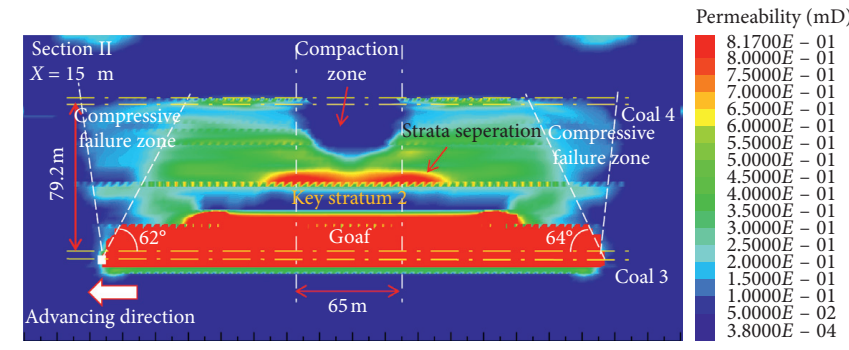

020406080100120140160180200220240260280300320340360380400

Strike length $(\mathrm{m})$

(c)

Figure 7: Permeability distribution characteristics in the coal 4 and strata: (a) slice along coal 4; (b) slice along inclined direction; (c) slice along advancing direction.

$0.817 \mathrm{mD}$, and when $X=190 \mathrm{~m}$ on the right side, the maximum permeability reaches $0.588 \mathrm{mD}$. The permeability of the PDCS shows a double peak in the inclined direction of the coal seam after compaction deformation, and its maximum is in the lower-middle part, followed by the uppermiddle part, and the lowest is in the middle part.

The permeability increases from the margin to the center in the " 0 "-shaped pressure relief and permeability enhancement zone. When the permeability reaches $3.5 \mathrm{mD}$, the gradient increases sharply. At this point, it can be concluded that $3.5 \mathrm{mD}$ is the threshold between the compressive failure zone (circle of increased stress in Figure 2) and the pressure relief zone. Based on this boundary, the pressure relief angles are $62^{\circ}, 64^{\circ}, 59^{\circ}$, and $66^{\circ}$ in the advancing direction, goaf direction, and uphill and downhill directions, respectively.
As shown in Sections II and III of Figure 7, the permeability enhancement zone is an inverted trapezoid, and the effective pressure relief range is a positive trapezoid. The effective pressure relief zone and compressive failure zone are bounded by the fault line of the rock stratum. Thus, the permeability of the PDCS in the effective pressure relief zone is obviously higher than that in the compressive failure zone.

At the boundary of longwall panel 11223 in the PDCS (i.e., point A in Section 1), the permeability decreases as the protective coal seam is mined due to the abutment pressure in the margin. As the working face advances, the high stress zone shifts further, and the permeability increases again (Figure $8(\mathrm{a})$ ). The permeability here is generally higher than the original value due to coal damage by the high stress concentration. At point $E$, the permeability remains static until the working face advances 


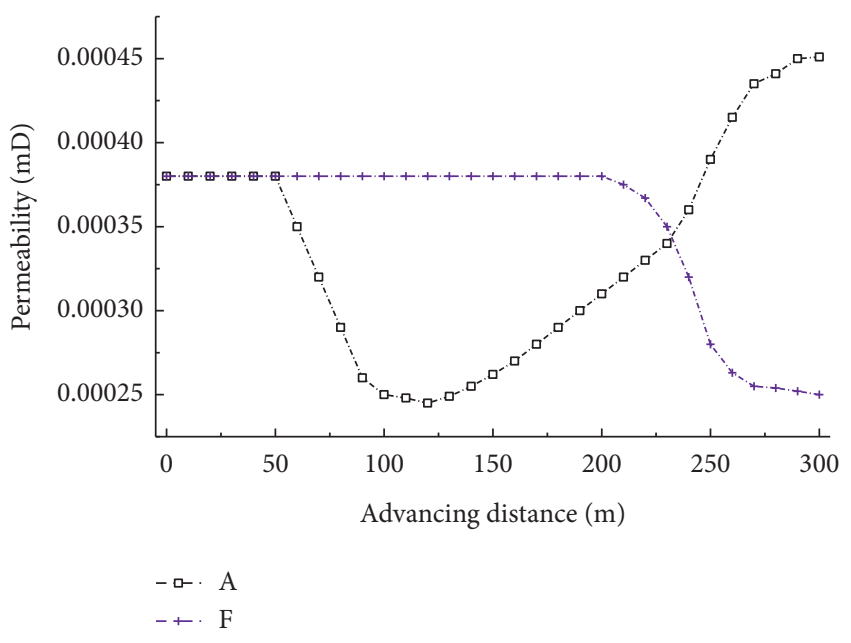

(a)

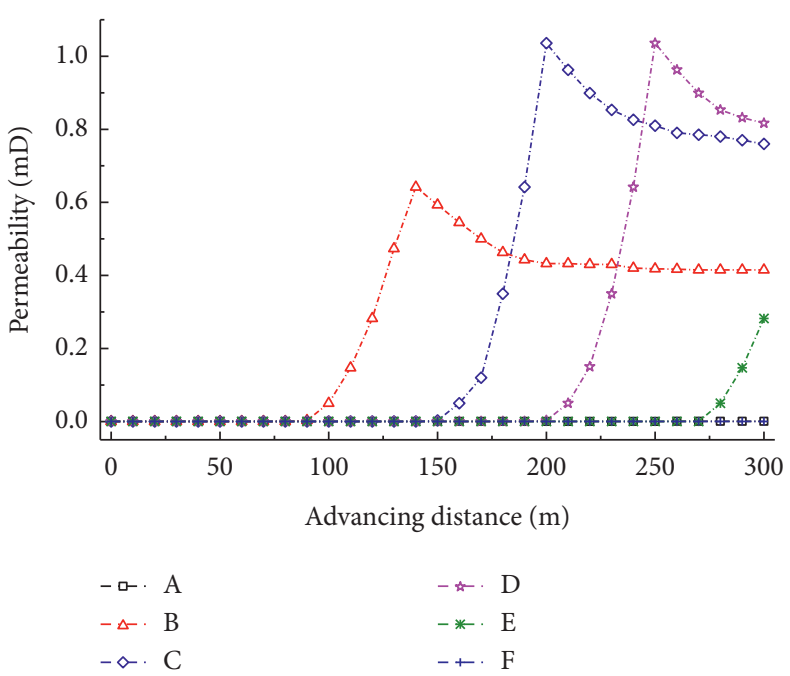

(b)

FIgURE 8: (a) Permeability changes during protective longwall face mining along $X=120$ and (b) magnified view of the $Y$-axis.

$210 \mathrm{~m}$. Then, the permeability decreases gradually due to the abutment stress increase caused by PCS mining. As both points $\mathrm{A}$ and $\mathrm{F}$ are located in the compressive failure zone, the permeability barely increases.

Because of points $\mathrm{B}, \mathrm{C}, \mathrm{D}$, and $\mathrm{E}$ located in the pressure relief zone, the permeabilities sharply increase to approximately $1.04 \mathrm{mD}$ when the working face advances to a certain distance (Figure 8(b)). Then, the permeability in the PDCS gradually decreases due to goaf compaction. However, the permeability is still much higher than the original value, indicating that PCS mining creates a significant positive effect on the pressure relief and permeability enhancement. However, due to the pressure relief angles in Figure 7, the permeability gradually increases until the protective longwall face advances by a certain distance from the monitoring points. In addition, the permeability decreases from the middle to the outside in the middle (e.g., points A, B, and C).

4.3. Distribution Characteristics of Gas Pressure. The technical criterion of the protective coal seam exploitation denotes that when the gas pressure drops below $0.74 \mathrm{MPa}$, the PDCS can be effectively protected [7]. The gas pressure distribution of coal 4 is shown in Figure 9 after a 300 m excavation of the panel 11223 . The range where the gas pressure is lower than $0.74 \mathrm{MPa}$ has a "0" shape and exhibits significant asymmetric distribution characteristics. On the one hand, the dip angle of the coal measurement causes asymmetric strata movement, resulting in the entire pressure relief zone shifting downward, which is approximately $30 \mathrm{~m}$ beyond the mining boundary. On the other hand, the gas pressure on the downhill side of the working face is effectively reduced, while the gas pressure at the uphill side decreases slightly, and the local gas pressure is still higher than $0.74 \mathrm{MPa}$. The permeability of the PDCS in the recompaction zone was recovered to the state before pressure relief mining, and the free gas was readsorbed, resulting in the gas pressure here still being higher than the threshold value. Based on the results of the numerical simulation, the excavation of coal 3 in group A displays a positive effect on releasing coal 4 in group B. Notably, the permeability and gas pressure will, to some extent, recover in the recompaction zone as the longwall face advances. Thus, the long-distance pressure relief mining of a high-gas coal seam must be combined with gas drainage to extract gas in the entire cycle of permeability change of the PDCS to achieve better protection of the PDCS.

\section{Engineering Verification}

The engineering practice of PCS mining in China and abroad shows that the PDCS can be effectively protected when the normal expansion deformation is greater than $0.6 \%$ [44]. Thus, the displacement of the roof and floor of coal 4 was measured by deep-base point displacement meters, and the coal seam swelling deformation was calculated. The deformation boreholes were arranged in the 11224 bottom drainage roadway, and boreholes $1 \#$ and $2 \#$ were $300 \mathrm{~m}$ and $290 \mathrm{~m}$ away from the stop line, respectively. The specific drilling parameters are shown in Table 5.

The measured swelling deformation of the PDCS changes with an advancement in the working face, ss shown in Figure 10. The swelling deformation of the PDCS increases slowly before the 11223 working face advances through borehole 1\# at $35 \mathrm{~m}$. The growth rate is relatively fast between $35 \mathrm{~m}$ and $50 \mathrm{~m}$, but the swelling deformation of the PDCS measured by the two deformation boreholes is less than $0.6 \%$. The swelling deformation of the PDCS increases sharply and exceeds $0.6 \%$ when the working face advances through the deformation boreholes at $50 \mathrm{~m}$. The maximum swelling deformations of the PDCS measured by boreholes $1 \#$ and $2 \#$ are $1.126 \%$ and $1.028 \%$, respectively. The results show that coal seam 4 (PDCS) is effectively protected by mining panel 11223 . The swelling deformation of coal 4 agrees with the permeability variation law in the numerical simulation, indicating that the numerical simulation is valid. 


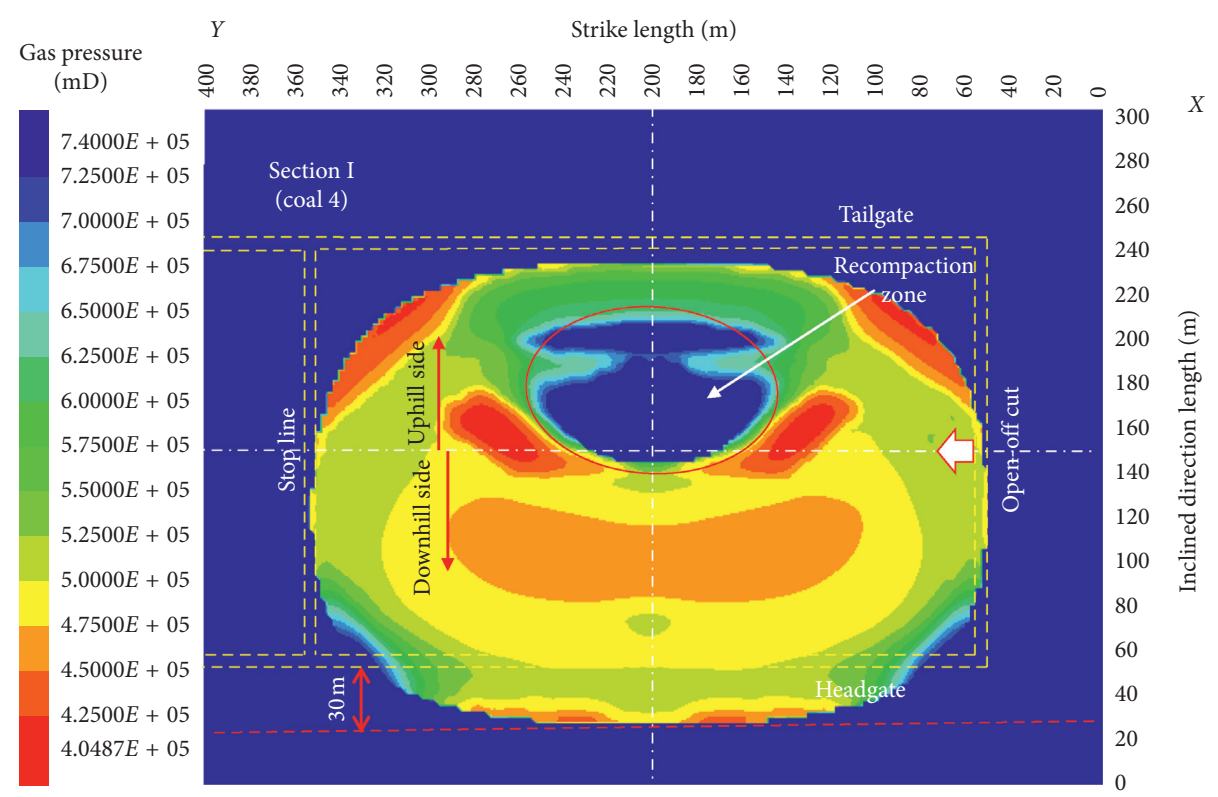

FIgURE 9: Distribution characteristics of gas pressure in coal 4.

TABle 5: Parameters of swelling deformation in the 11224 bottom drainage roadway.

\begin{tabular}{lcccc}
\hline Borehole & $\begin{array}{c}\text { Borehole } \\
\text { diameter }(\mathrm{mm})\end{array}$ & Position & $\begin{array}{c}\text { Elevation } \\
\text { angle }\left(^{\circ}\right)\end{array}$ & $\begin{array}{c}\text { Borehole } \\
\text { depth }(\mathrm{m})\end{array}$ \\
\hline $1 \#$ & 75 & $\begin{array}{c}\text { Roadway } \\
\text { wall } \\
2 \#\end{array}$ & 70 & 29.5 \\
\hline
\end{tabular}

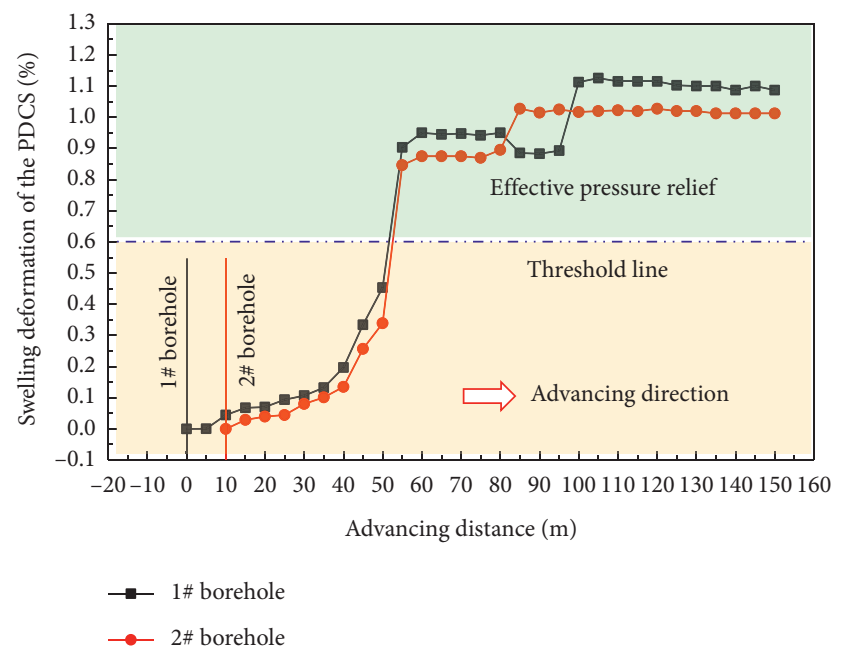

Figure 10: Expansion deformation measurement of the protected coal seam.

\section{Discussion}

Currently, field measurements and numerical simulations are widely employed to test the effect of pressure relief and permeability enhancement in PDCS. In this study, the effects of long-distance pressure relief and permeability enhancement in deep high-gassy coal seams are analyzed via numerical simulations and field measurements. The extraction of coal 3 in group A appears to have a positive effect on the permeability enhancement and pressure relief gas drainage of coal 4 in the Paner colliery. However, it is difficult to realize the simultaneous simulation of pressure relief mining and gas drainage in the protected layer using FLAC3D because coal seam mining has a large deformation scale and the gas drainage borehole has a small deformation scale. In fact, the current related studies also simulate pressure relief mining and gas drainage, separately. Generally, the surrounding rock is usually divided into different zones based on the damage degree to establish stress permeability or strain permeability under the large deformation condition of pressure relief mining $[17,18,25,26]$. The simulation of gas drainage considers microscale factors, e.g., adsorption and desorption of coal seam gas, pore structure, and capillary force, ignoring the large deformation of coal seams caused by mining $[36,42]$. In addition, the development of numerical models requires simplifying the field engineering and geological settings, and the ideal constitutive model and boundary conditions should be adopted. Therefore, the results of the numerical simulation can only provide a reference for engineering, and field tests are necessary before technology implementation.

Due to the poor gas drainage effect without pressure relief mining, the combination method of pressure relief mining and gas drainage is an important measure to prevent coal and gas outbursts in the Huainan mining area [2, 3]. Before protective layer mining, the gas in the protected layer is predrained until the end of protective layer mining, and the drainage borehole is scrapped. This method can extract the pressure relief gas in time and avoid the problem of permeability and gas pressure recovery in the recompacted area in the numerical simulation, which leads to the failure 


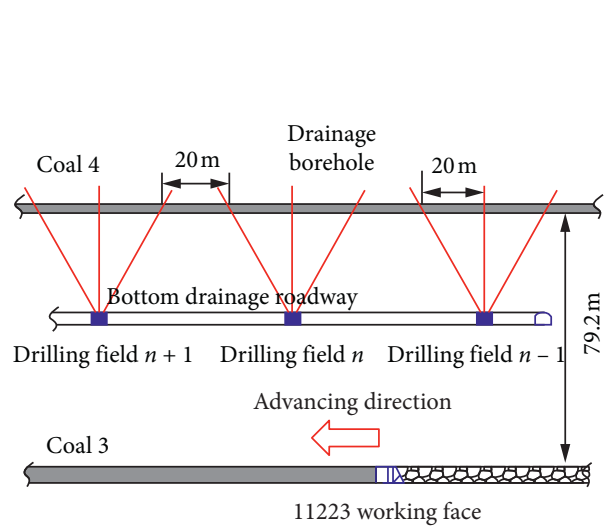

(a)

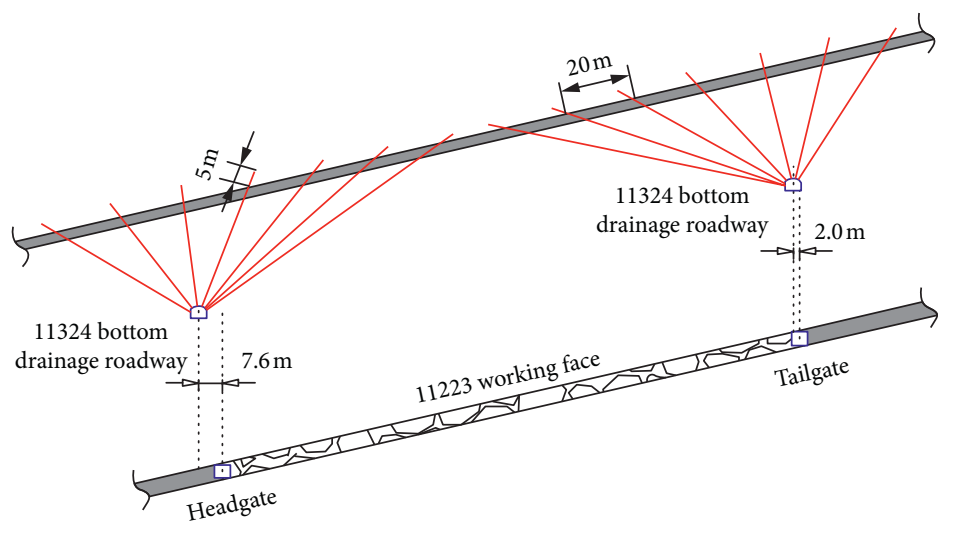

(b)

FIGURE 11: Layout of boreholes for pressure relief gas drainage in the east district [45]: (a) strike direction; (b) inclined direction.

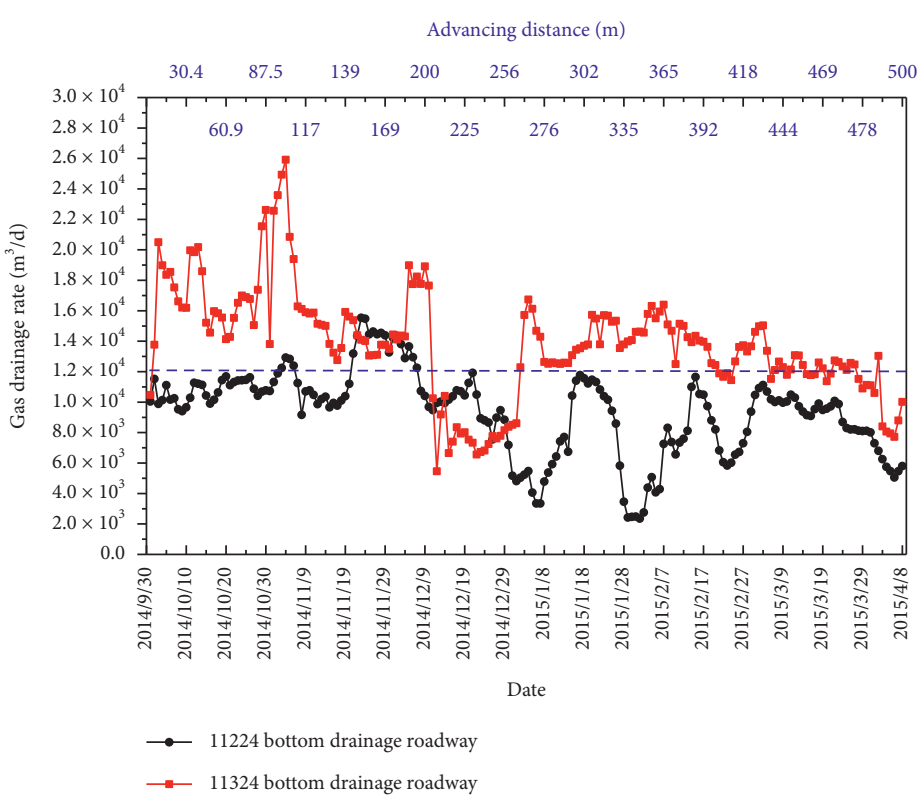

(a)

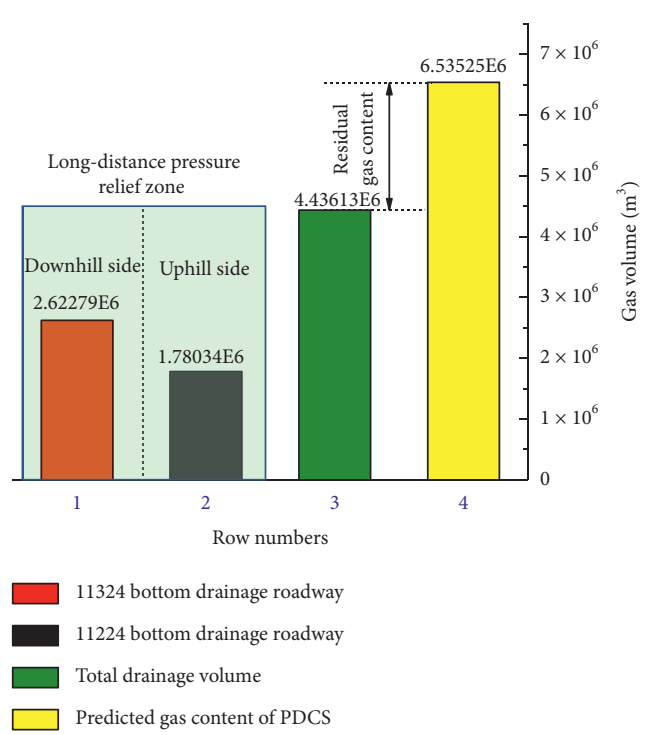

(b)

FIGURE 12: Statistics of the pressure relief gas extraction volume: (a) real-time extraction volume; (b) total extraction volume.

of effective pressure relief in the recompaction zone of the protected layer.

Figure 11 shows the typical grid layout of upward boreholes at bottom drainage roadways for pressure relief gas drainage in the Huainan mining area. The drilling fields were arranged into 70 groups (including the west district) and 33 groups at the 11224 and 12324 bottom drainage roadways, respectively. Three rows of gas drainage boreholes are drilled in each drilling field with the borehole row spacing of $20 \times 20 \mathrm{~m}$, a drainage borehole diameter of $94 \mathrm{~mm}$, and a sealing depth of $5 \mathrm{~m}$. The vertical distance between the bottom drainage roadway and coal 3 is $46.6 \mathrm{~m}$. The horizontal outside interval of the 11324 bottom drainage roadway and the headgate is $7.6 \mathrm{~m}$, and the horizontal inside interval is $2.0 \mathrm{~m}$ between the 11224 bottom drainage roadway and tailgate. The drainage negative pressure of the boreholes is $24 \mathrm{kPa}$ and $28 \mathrm{kPa}$ in the 11324 and 11224 bottom drainage roadways, respectively.

The gas drainage volume of coal 4 within $500 \mathrm{~m}$ from the entry of panel 11223 into the east district is shown in Figure 12. The pressure relief gas drainage volume of the 11324 bottom drainage roadway is maintained at $5000-26000 \mathrm{~m}^{3} / \mathrm{d}$ and that of the 11224 bottom drainage roadway is maintained at $2000-16000 \mathrm{~m}^{3} / \mathrm{d}$. As the working face advances, the pressure relief zone of the PDCS increases, the gas is desorbed and extracted, and the gas content in the coal seam is greatly reduced, which leads to an attenuation trend of the gas drainage volume of the bottom drainage roadway. In this period, the total volume of gas drainage in the 11324 bottom drainage roadway is $2622790 \mathrm{~m}^{3}$, with an average of $13804.16 \mathrm{~m}^{3} / \mathrm{d}$, and that of the 11224 bottom drainage roadway is $1780337 \mathrm{~m}^{3}$, with an average of $9370.19 \mathrm{~m}^{3} / \mathrm{d}$. The latter is $67.88 \%$ of the former, 
indicating that the effect of pressure relief and permeability enhancement in the downhill side of the inclined working face is better than that of the uphill side, and the asymmetric distribution of permeability and gas pressure in the numerical simulation is verified. Furthermore, the gas drainage rate of the PDCS reaches $69.59 \%$, which fully indicates that it is valid to take coal 3 as the PCS for the long-distance release of coal 4 in the Huainan mining area.

\section{Conclusions}

Based on an analysis of the simulation results and field measurements, the main conclusions are as follows:

(1) The extraction of coal 3 in group A appears to have a positive effect on releasing long-distance coal 4 in group $\mathrm{B}$ in the Paner coal mine. The numerical simulation shows that the permeability of the PDCS is increased by a maximum of 2149 times, and the gas pressure is reduced to below $0.74 \mathrm{MPa}$. The field measurements show that the maximum swelling deformation is $1.126 \%$, and the gas drainage rate of the PDCS is $69.59 \%$.

(2) The permeability effective enhancement zone (pressure relief zone) is a regular trapezoid with pressure relief angles of $62^{\circ}, 64^{\circ}, 59^{\circ}$, and $66^{\circ}$ in the advancing direction, goaf direction, uphill direction, and downhill direction, respectively. The permeability in the compressive zone is improved to a certain extent but is lower than that in the pressure relief zone.

(3) The dip angle of coal measures causes an asymmetric strata movement, which leads to the pressure relief and permeability enhancement area shifting to the downhill side, where the permeability enhancement effect of the downhill side is better than that of the uphill side.

(4) The permeability in the pressure relief zone will decrease again due to the recompaction of the coal seam with the advancement of the longwall face. Thus, pressure relief gas drainage is suggested during long-distance protective coal seam mining to eliminate gas hazards.

\section{Data Availability}

The data used to support the findings of this study are available from the corresponding author upon request.

\section{Conflicts of Interest}

The authors declare that they have no conflicts of interest.

\section{Acknowledgments}

Financial support for this work was provided by the University Synergy Innovation Program of Anhui Province (GXXT-2019-029) and the innovation team of Anhui
University of Science and Technology on coal safety and precision mining, multifield coupling disaster mechanism and monitoring, and early warning (115 innovation teams in Anhui Province).

\section{References}

[1] M. G. Qian, X. X. Miao, and J. L. Xu, "Green mining of coal resources harmonizing with environment," Journal of China Coal Society, vol. 32, no. 1, pp. 1-7, 2007.

[2] L. Yuan, "Control of coal and gas outbursts in Huainan mines in China: a review," Journal of Rock Mechanics and Geotechnical Engineering, vol. 8, no. 4, pp. 559-567, 2016.

[3] L. Yuan, H. Guo, and B. T. Shen, "Circular overlying zone at longwall panel for efficient methane capture of multiple coal seams with low permeability," Journal of China Coal Society, vol. 36, no. 3, pp. 357-365, 2011.

[4] Y.-P. Cheng, L. Wang, and X.-L. Zhang, "Environmental impact of coal mine methane emissions and responding strategies in China," International Journal of Greenhouse Gas Control, vol. 5, no. 1, pp. 157-166, 2011.

[5] B. Guo, Y. Li, F. Jiao, T. Luo, and Q. Ma, "Experimental study on coal and gas outburst and the variation characteristics of gas pressure," Geomechanics and Geophysics for Geo-Energy and Geo-Resources, vol. 4, no. 4, pp. 355-368, 2018.

[6] L. Wang, Y.-P. Cheng, and H.-Y. Liu, "An analysis of fatal gas accidents in Chinese coal mines," Safety Science, vol. 62, pp. 107-113, 2014.

[7] State Administration of Work Safety, Coal Mine Safety Regulations (2016 Version), China Coal Industry Publishing House, Beijing, China, 2016.

[8] D. Shu, J. Chamberlain, C. Lakshmanan, and N. White, "Estimation of in situ coal permeability and modeling of methane pre-drainage from in-seam holes," in Proceedings of the International Symposium on Cum Workshop on Management and Control of High Gas Emissions and Outbursts in Underground Coal Mines, pp. 303-310, Wollongong, Australia, December 1995.

[9] T. Xia, F. Zhou, J. Liu, S. Hu, and Y. Liu, "A fully coupled coal deformation and compositional flow model for the control of the pre-mining coal seam gas extraction," International Journal of Rock Mechanics and Mining Sciences, vol. 72, pp. 138-148, 2014

[10] C. Zhang, S. Tu, Q. Bai, G. Yang, and L. Zhang, "Evaluating pressure-relief mining performances based on surface gas venthole extraction data in longwall coal mines," Journal of Natural Gas Science and Engineering, vol. 24, pp. 431-440, 2015.

[11] F. Zhou, T. Xia, X. Wang, Y. Zhang, Y. Sun, and J. Liu, "Recent developments in coal mine methane extraction and utilization in China: a review," Journal of Natural Gas Science and Engineering, vol. 31, pp. 437-458, 2016.

[12] S. Sang, H. Xu, L. Fang, G. Li, and H. Huang, "Stress relief coalbed methane drainage by surface vertical wells in China," International Journal of Coal Geology, vol. 82, no. 3-4, pp. 196-203, 2010.

[13] F. Wang, T. Ren, S. Tu, F. Hungerford, and N. Aziz, "Implementation of underground longhole directional drilling technology for greenhouse gas mitigation in Chinese coal mines," International Journal of Greenhouse Gas Control, vol. 11, pp. 290-303, 2012.

[14] C. Zhang, S. Tu, L. Zhang, Q. Bai, Y. Yuan, and F. Wang, "A methodology for determining the evolution law of gob 
permeability and its distributions in longwall coal mines," Journal of Geophysics and Engineering, vol. 13, no. 2, pp. 181193, 2016.

[15] S. G. Li, H. F. Lin, and P. X. Zhao, "Dynamic evolution of mining fissure elliptic paraboloid zone and extraction coal and gas," Journal of China Coal Society, vol. 39, no. 8, pp. 14551462, 2014.

[16] Y. P. Cheng, H. Y. Liu, P. K. Guo, R. K. Pan, and L. Wang, “A theoretical model and evolution characteristic of miningenhanced permeability in deeper gassy coal seam," Journal of China Coal Society, vol. 39, no. 8, pp. 1650-1658, 2014.

[17] S. H. Tu, C. Zhang, G. Y. Yang, Q. S. Bai, and R. L. Yan, "Research on permeability evolution law of goaf and pressurerelief mining effect," Journal of Mining and Safety Engineering, vol. 33, no. 4, pp. 571-577, 2016.

[18] J. L. Xu, Distribution Law of Mining-Induced Strata Factures and its Applications, China University of Mining and Technology Press, Xuzhou, China, 2016.

[19] Z. H. Zhu, T. Feng, Z. G. Yuan, D. H. Xie, and W. Chen, "Solid-gas coupling model for coal-rock mass deformation and pressure relief gas flow in protection layer mining," Advances in Cival Engineering, vol. 2018, no. 6, Article ID 5162628, 2018.

[20] Z. G. Yuan, Y. H. Shao, and Z. H. Zhu, "Similar material simulation study on protection effect of steeply inclined upper protective layer mining with varying interlayer distances," Advances in Cival Engineering, vol. 2019, no. 14, Article ID 9849635, 2019.

[21] C. Zhang, Q. S. Bai, and Y. H. Chen, "Using stress pathdependent permeability law to evaluate permeability enhancement and coalbed methane flow in protected coal seam: a case study," Geomechanics And Geophysics for Geo-Energy And Geo-Resources, vol. 6, no. 3, pp. 1-25, 2020.

[22] N. Baptiste and R. P. Chapuis, "What maximum permeability can be measured with a monitoring well?" Engineering Geology, vol. 184, no. 111-118, 2015.

[23] W. Barrash, T. Clemo, J. J. Fox, and T. C. Johnson, "Field, laboratory, and modeling investigation of the skin effect at wells with slotted casing, Boise Hydrogeophysical Research Site," Journal of Hydrology, vol. 326, no. 1-4, pp. 181-198, 2006.

[24] Q. Liu, P. Chu, J. Zhu et al., "Numerical assessment of the critical factors in determining coal seam permeability based on the field data," Journal of Natural Gas Science and Engineering, vol. 74, Article ID 103098, 2020.

[25] C. Zhang, S. Tu, and L. Zhang, "Field measurements of compaction seepage characteristics in longwall mining goaf," Natural Resources Research, vol. 29, no. 2, pp. 905-917, 2019.

[26] Q. S. Bai, S. H. Tu, and C. Wang, "Numerical simulation on top-coal arching mechanism," Journal of Mining and Safety Engineering, vol. 31, no. 2, pp. 208-213, 2014.

[27] C. Rabe, P. R. R. Perdomo, P. F. Roux, C. G. Silva, and P. Gamboa, "Coupled fluid flow and geomechanics: a case study in Faja del Orinoco," Springer Series in Geomechanics and Geoengineering, vol. 6, no. 1, 2020.

[28] X. Liu, X. Wang, E. Wang et al., "Effects of gas pressure on bursting liability of coal under uniaxial conditions," Journal of Natural Gas Science and Engineering, vol. 39, pp. 90-100, 2017.

[29] Z. Yin, W. Chen, H. Hao et al., "Dynamic compressive test of gas-containing coal using a modified Split Hopkinson pressure bar system," Rock Mechanics And Rock Engineering, vol. 53, no. 2, pp. 815-829, 2020.
[30] G. Yin, C. Jiang, J. G. Wang, and J. Xu, "Combined effect of stress, pore pressure and temperature on methane permeability in anthracite coal: an experimental study," Transport in Porous Media, vol. 100, no. 1, pp. 1-16, 2013.

[31] C. Zhang and L. Zhang, "Permeability characteristics of broken coal and rock under cyclic loading and unloading," Natural Resources Research, vol. 28, no. 3, pp. 1055-1069, 2019.

[32] C. Zhang, L. Zhang, and W. Wang, "The axial and radial permeability testing of coal under cyclic loading and unloading," Arabian Journal of Geosciences, vol. 12, no. 11, p. 19, 2019.

[33] Z. Q. Jiang, L. J. Ji, R. S. Zuo, and L. Cao, “Correlativity among rock permeability and strain-stress under servo-control condition," Chinese Journal of Rock Mechanics and Engineering, vol. 21, no. 10, pp. 1442-1446, 2002.

[34] P. Lu, Z. W. Shen, G. W. Zhu, and E. Fang, "Characterization of and experimental study on the permeability of rocksamples during complete stress-strain course," Journal of University of Science and Technology of China, vol. 32, no. 6, pp. 45-51, 2002.

[35] R. R. Jozefowicz, "The post-failure stress-permeability behaviour of coal measure rocks," Doctoral dissertation, University of Nottingham, Nottingham, UK, 1997.

[36] Q. S. Bai, S. H. Tu, and Y. Yuan, "Back analysis of mining induced responses on the basis of goaf compaction theory," Journal of China University of Mining and Technology, vol. 42, no. 3, pp. 355-361, 2013.

[37] S. Durucan, An Investigation into the Stress Permeability Relationship of Coals and Flow Patterns Around Working Longwall Faces, University of Nottingham, Nottingham, UK, 1981.

[38] D. N. Whittles, I. S. Lowndes, S. W. Kingman, C. Yates, and S. Jobling, "Influence of geotechnical factors on gas flow experienced in a UK longwall coal mine panel," International Journal of Rock Mechanics and Mining Sciences, vol. 43, no. 3, pp. 369-387, 2006.

[39] T. X. Ren and J. S. Edwards, "Goaf gas modeling techniques to maximize methane capture from surface gob wells," Mine Ventilation, vol. 2, pp. 279-286, 2002.

[40] W. Yang, B.-Q. Lin, Q. Yan, and C. Zhai, "Stress redistribution of longwall mining stope and gas control of multi-layer coal seams," International Journal of Rock Mechanics and Mining Sciences, vol. 72, pp. 8-15, 2014.

[41] G. S. Esterhuizen and C. Ö Karacan, "Development of numerical models to investigate permeability changes and gas emission around longwall mining panels," in Proceedings of the 40th U. S. Symposium on Rock Mechanics, pp. 25-26, Anchorage, AK, USA, June 2005.

[42] C. Zhang, S. H. Tu, and Y. Yuan, "Numerical simulation of surface gas venthole extraction in pressure relief mining," Journal of China Coal Society, vol. 40, no. s2, pp. 392-400, 2015.

[43] F. Wang, C. Zhang, and N. Liang, "Gas permeability evolution mechanism and comprehensive gas drainage technology for thin coal seam mining," Energies, vol. 10, no. 9, p. 1382, 2017.

[44] B. F. Yu, Study and Practice of Mining Protective Layer, pp. 86-107, China Coal Industry Publishing House, Beijing, China, 1986.

[45] X. He, K. Yang, L. Yuan, C. Zhang, and T. Zhang, "Experimental study of pressure-relief and permeability improvement effect of the remote protected layer crossing coal groups with double key strata," Journal of China University of Mining and Technology, vol. 49, no. 2, pp. 238-246, 2020. 